\title{
Joint production of biodiesel and bioethanol from filamentous oleaginous microalgae Tribonema sp.
}

\author{
Hui Wang ${ }^{a}$, Chunli Ji ${ }^{\text {a,b }}$, Shenglei Bi ${ }^{c}$, Peng Zhou ${ }^{c}$, Lin Chen ${ }^{a}$, Tianzhong Liu ${ }^{\text {a,* }}$ \\ a Key Laboratory of Biofuels, Qingdao Institute of Bioenergy and Bioprocess Technology, Chinese Academy of Sciences, Qingdao, Shandong 266101, PR China \\ ${ }^{\mathrm{b}}$ University of Chinese Academy of Sciences, Beijing 100049, PR China \\ ' State Key Laboratory of Motor Vehicle Biofuel Technology, Nanyang, Henan 473000, PR China
}

\section{H I G H L I G H T S}

- A sugar and oil-rich Tribonema strain was used for ethanol and biodiesel production.

- Acidic hydrolysis can efficiently saccharify microalgae biomass and release lipid.

- Acidic hydrolysis method promoted the transformation of PL to FFA in lipid.

- Bioethanol yield from hydrolysate is similar to the theoretical yield.

\section{A R T I C L E I N F O}

\section{Article history:}

Received 31 July 2014

Received in revised form 4 September 2014

Accepted 5 September 2014

Available online 16 September 2014

\section{Keywords:}

Tribonema sp.

Lipid

Bioethanol fermentation

Acid hydrolysis

\begin{abstract}
A B S T R A C T
Making full use of lipid and carbohydrate in microalgae for joint production of biodiesel and bioethanol may create a potential way to cut the high cost of single biofuel production from microalgae. Compared with conventional unicellular oleaginous microalgae, filamentous microalgae Tribonema sp. is richer in lipid and carbohydrate contents and lower protein content, thus, this study explores the suitability of Tribonema sp. as a substrate for joint production of biodiesel and bioethanol. Acid hydrolysis is the key step to saccharify wall cell into fermentable sugar and release lipid. Microalgae biomass $(50 \mathrm{~g} / \mathrm{L})$ was acid ( $3 \% \mathrm{H}_{2} \mathrm{SO}_{4}$ ) hydrolyzed at $121^{\circ} \mathrm{C}$ for $45 \mathrm{~min}$ to reach the maximum hydrolysis efficiency (81.48\%). Subsequently, the lipid separated with hexane-ethanol from the hydrolysate was converted into microalgae biodiesel and the conversion rate was $98.47 \%$. With yeast Saccharomyces cerevisiae, the maximum ethanol yield of $56.1 \%$ was reached from $14.5 \mathrm{~g} / \mathrm{L}$ glucose in hydrolysate.
\end{abstract}

(c) 2014 Elsevier Ltd. All rights reserved.

\section{Introduction}

Currently, microalgae-based biodiesel production has been the focus of attention for the scientific community for an extended period of time (Chisti, 2007; Mata et al., 2010). However, the industrialization production of single biodiesel production from microalgae still faced with the commercial barrier of high cost (Logan and Ronald, 2011). In fact, besides lipid, microalgae are sunlight-driven cell factories that convert carbon dioxide to carbohydrate, which could also be considered as source for bioethanol production (Efremenko et al., 2012). In addition, microalgae based bioethanol fermentation display greater sustainable and commercial advantages over lignocellulosic biomass. Microalgae based carbohydrates are mainly in the form of polysaccharide, starch and cellulose (with the absence of lignin and low hemicelluloses content), these

\footnotetext{
* Corresponding author. Tel./fax: +86 53280662735.

E-mail address: liutz@qibebt.ac.cn (T. Liu).
}

carbohydrates are much easier to convert to fermented monosaccharides (Harun et al., 2010; Harun and Danquah, 2011; John et al., 2011). Therefore, making full use of lipid and carbohydrate in microalgae biomass as feedstock for joint production of biodiesel and bioethanol creates a potential way to cut the high cost of single biofuel production from microalgae.

In order to realize biodiesel conversion and bioethanol fermentation, microalgae biomass needs to be processed in order to extract lipid and release sugar (Talukder et al., 2012). Ultrasonication method and cycled freezing - thawing method have been widely used to break the cell wall of microalgae for lipid extraction (Huang et al., 2014; Silva et al., 2014). However, large scale lipid extraction using ultrasonication method or freezing-thawing method is no doubt to be less efficient and time consuming. Considering the lipid droplets are in thylakoid enveloped by cell walls, a reasonable way may be the hydrolysis, resulting the fully disruption of cell structure to release lipid oil and saccharification simultaneously. Thus, the hydrolysis of carbohydrate in terms of 
cellulose/polysaccharide on cell walls and starch in chloroplasts to fermentable sugar is the key step (Ho et al., 2013; Razif and Michael, 2011). In general, chemical (acid and alkaline) or enzymatic hydrolysis are common methods used for carbohydrate hydrolysis (Chen et al., 2013; Lynd et al., 2002). While enzymatic hydrolysis is an environmentally benign process and can obtain higher glucose yields without producing inhibitory products, but it is slower and much more expensive than chemical hydrolysis (Harun et al., 2010; Lynd et al., 2002). In addition, since most microalgae have been reported to have no lignin composition in cell wall (Ho et al., 2013), the dilute acidic hydrolysis is, therefore, needed to make microalgal biofuels commercially competitive.

Though there is a theoretical feasibility to jointly produce biodiesel and bioethanol with oleaginous microalgae, the practicability is problematic because almost all the reported oleaginous microalgae are conventional unicellular species such as Chlorella, Scenedesmus and Nannochloropsis sp., which have higher proteins than polysaccharidable components apart from the lipids. The worse emulsification of hydrolyzed proteins hampers the saccharification and the separation of lipid, resulting in the low fermentable sugar and lipid content.

Microalgae Tribonema sp. is a special filamentous oleaginous microalgae which could accumulate high lipids and carbohydrates, but much less proteins than conventional unicellular oleaginous species (Guo et al., 2014). Here this present work further explores the suitability of this species as feedstock for joint production of biodiesel and bioethanol via acid hydrolysis. The effects of different acid hydrolysis conditions and fermentation parameters on the yield of biodiesel and bioethanol were described.

\section{Methods}

\subsection{Microalgae biomass}

Tested microalgae strain Tribonema sp. was provided by the Culture Collection of Algae of Gottingen University. Microalgae biomass (dry) was harvested from column photobioreactors with 20 L of BG11 medium. The total lipid and carbohydrate contents in the biomass were determined according to the methods reported by Guo et al. (2014), and found to be $48.7 \%$ and $31.2 \%$ of dry weight, respectively.

\subsection{Acid hydrolysis}

For the acid hydrolysis, sulfuric acid was used as the acidic regent. The same weight microalgae biomass were loaded into different dilute sulfuric acid with concentrations of $1-17 \%(v / v)$ to reach a loading concentration of $50 / \mathrm{L}$ ( $5 \%$ biomass loading). After confirming the optimal dilute concentration, different loadings (10-200 g/L; $1-20 \%$ solid to liquid ratio) of dry microalgae biomass were mixed with fixed optimal dilute sulfuric acid. The resulting slurries were then autoclaved at $121^{\circ} \mathrm{C}$ for $0.5-2 \mathrm{~h}$, respectively. After hydrolysis, the samples were cooled to room temperature, centrifuged at $8000 \mathrm{rpm}$ for $10 \mathrm{~min}$, and the supernatant containing the released sugars was collected as acidic hydrolysate, and the sugar content was measured.

\subsection{Lipid extraction}

After acid pretreatment, a certain amount of hydrolyzed microalgae was loaded into ethanol-hexane $(1: 3, v / v)$ as a ratio of biomass: solvent of $1: 6(\mathrm{w} / \mathrm{v})$. The mixture was incubated at around $50{ }^{\circ} \mathrm{C}$ for $0-2.5 \mathrm{~h}$ in a shaker incubator. And then the lipid was separated into hexane and aqueous ethanol layer by the addition of $\mathrm{H}_{2} \mathrm{O}$ to give a final solvent ratio of ethanol: $\mathrm{H}_{2} \mathrm{O}$ of 1:0.9. After that, the hexane phase was collected and the lipid content was analyzed by gravimetric method.

The composition of lipid was analyzed using a thin-layer chromatography system (TLC-FID, Mk-6, latron Laboratories, Inc., Japan) (Fedosov et al., 2011). The individual lipid component was identified by co-chromatography with pure standards (SE\&HC; FAME; FFA; TAG; DAG; MAG\&PL, purchased from Sigma, St. Louis, MO. USA).

\subsection{Biodiesel production from lipid}

To make the transesterification reaction, a $5 \mathrm{~g}$ lipid sample was mixed with $2 \mathrm{ml}$ methanol containing $3.3 \%$ sulfuric acid, and heated at $65^{\circ} \mathrm{C}$ for $120 \mathrm{~min}$. After that, $2 \mathrm{ml}$ methanol containing potassium hydroxide $(\mathrm{KOH})$ were added into the mixture at $65^{\circ} \mathrm{C}$ for $30 \mathrm{~min}$ (Chen et al., 2012). Finally, the mixture was cooled at room temperature and solvent was evaporated.

The fatty acid methyl esters (FAMEs) composition was analyzed by means of gas chromatography as described by Wang et al. (2013). A $0.5 \mathrm{mg}$ sample of biodiesel was dissolved in $1 \mathrm{~mL}$ heptanes containing $50 \mu \mathrm{g}$ heptadecanoic acid methyl ester $\left(\mathrm{C}_{18} \mathrm{H}_{37}\right.$ $\left.\mathrm{COOCH}_{3}\right)$ as internal standard for FAME analysis on a Varian 450GC (Varian Inc., USA) equipped with a flame ionization detector (FID) and Agilent HO-5 GC Capillary Column. The individual FAMEs were identified by comparing their retention time against those of authentic standards.

\subsection{Fermentation medium preparation}

The pretreated microalgae biomass $(50 \mathrm{~g} / \mathrm{L})$ was mixed with $3.0 \%(\mathrm{v} / \mathrm{v})$ sulfuric acid to carry out acid hydrolysis based on the procedures mentioned earlier. After that, the acidic hydrolysate was adjusted to $\mathrm{pH}$ 5.5-6.0 with $\mathrm{CaCO}_{3}$, and the formed solid precipitate was removed by centrifuging at $5000 \mathrm{rpm}$ for $10 \mathrm{~min}$. The liquid phase was further filtered via a vacuum pump with a $0.2 \mu \mathrm{m}$ cellulose membrane filter, and then sterilized at $121^{\circ} \mathrm{C}$ for $20 \mathrm{~min}$ as fermentation medium for production of bioethanol.

\subsection{Bioethanol fermentation}

The bioethanol production of hydrolyzed microalgae biomass to ethanol was fermented by yeast Saccharomyces cerevisiae, the cells of which were pre-cultured in YPD medium $(10 \mathrm{~g} / \mathrm{L}$ yeast extract, $20 \mathrm{~g} / \mathrm{L}$ peptone and $20 \mathrm{~g} / \mathrm{L}$ glucose, pH5.4) to logarithmic growth phase. The pre-cultured yeast cells were centrifuged at $5000 \mathrm{rpm}$ for $10 \mathrm{~min}$ and then inoculated to the solution of the sterilized hydrolysate at an inoculum size of $10 \%$. The fermentation was carried at a constant temperature of $30^{\circ} \mathrm{C}$ in a desktop fermentor.

\section{Results and discussion}

\subsection{Acid hydrolysis of microalgae biomass}

The variation of dilute sulfuric acid concentration in the range of $1.0-17 \%(\mathrm{v} / \mathrm{v})$ was investigated during acid hydrolysis of microalgae biomass. Further analysis of hydrolysates by HPLC revealed the relative content of glucose to approximately $75 \% \mathrm{~g} / \mathrm{g}$ of total sugars, the second most abundant monosaccharide was xylose followed by galactose and mannose. Fig. 1 presented the effect of acid concentration on sugar and glucose release from microalgae biomass. The maximum of $18.8 \mathrm{~g} / \mathrm{L}$ of sugar concentration was obtained and $81.6 \%$ of sugar available in the microalgae biomass (dry) was released after 30 min of hydrolysis with $3 \%(\mathrm{v} / \mathrm{v})$ or higher $\mathrm{H}_{2} \mathrm{SO}_{4}$ at $121{ }^{\circ} \mathrm{C}$, while the glucose concentration reached maximum $(14.1 \mathrm{~g} / \mathrm{L})$ at acid concentration of $5 \%(\mathrm{v} / \mathrm{v})$. Ho et al. 


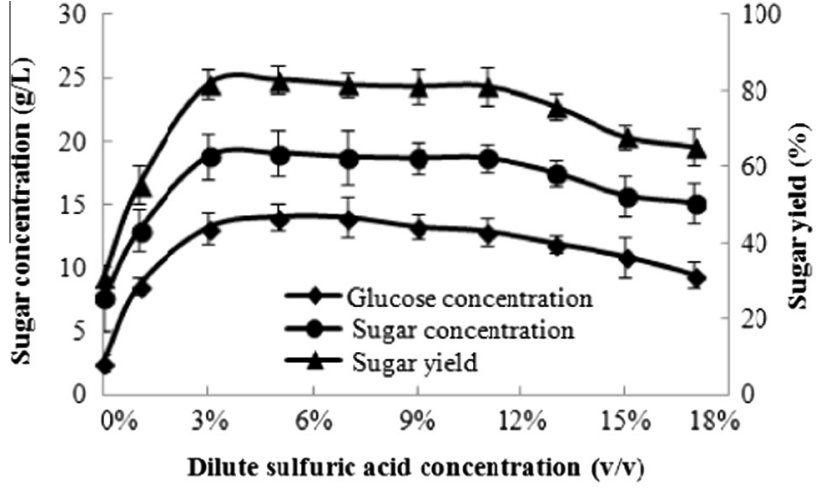

Fig. 1. Effect of acid concentration on sugars release from microlgae biomass. Hydrolysis conditions: $5 \%$ biomass loading $(\mathrm{w} / \mathrm{v})$, temperature $121^{\circ} \mathrm{C}$, time $0.5 \mathrm{~h}$.

(2013) reported that, total carbohydrate yields of nearly 100\% was obtained when the acid concentration was $2.5 \%$ or higher, but the biomass loading (solid-to-liquid ratio, w/v) was $1 \%$, quite lower than $5 \%$ in our study. However, Fig. 1 also showed the sugar contents and sugar yield began to decrease when the dilute acid concentration was over $11 \%$. It might because high acid concentration causes side reactions leading to the degradation of glucose and xylose to furfural and HMF, thereby reducing sugar yield (Talukder et al., 2012). Considering the need to minimize the dosage of acid, sulfuric acid concentration of $3.0 \%(\mathrm{v} / \mathrm{v})$ seems to be preferable in the acid hydrolysis, which was also recommended by Lee et al. (2011).

The experiment with different biomass loadings were performed at a fixed condition: $3 \% \mathrm{H}_{2} \mathrm{SO}_{4}, 121{ }^{\circ} \mathrm{C}$ and $30 \mathrm{~min}$. Fig. 2 revealed that the total sugar and glucose concentrations increased significantly from $2.7 \mathrm{~g} / \mathrm{L}$ to $51.5 \mathrm{~g} / \mathrm{L}$ and $2.4 \mathrm{~g} / \mathrm{L}$ to $40.2 \mathrm{~g} / \mathrm{L}$, respectively, when the microalgae loading increased from $10 \mathrm{~g} / \mathrm{L}$ to $200 \mathrm{~g} /$ L (or a solid-to-liquid ratio of 1-20\%). Sugar concentration increased with increasing biomass loading but did not follow a linear relationship after biomass loading of $50 \mathrm{~g} / \mathrm{L}$. Hence, the sugar yield dropped from $81.27 \%$ to $57.13 \%$ when biomass loading increased from $50 \mathrm{~g} / \mathrm{L}$ to $200 \mathrm{~g} / \mathrm{L}$. The result suggested that the low dispersion of sugar due to the limited space in the reaction vessel might reduce the hydrolysis rate at a higher biomass load and end-product inhibition (Szczodrak, 1988). Therefore, the biomass loading of $50 \mathrm{~g} / \mathrm{L}$ (or a solid-to-liquid ratio of 5\%), which was higher than those reported in previous literature (Ho et al., 2013; Razif and Michael, 2011), was chosen to investigate the effect of hydrolysis time,

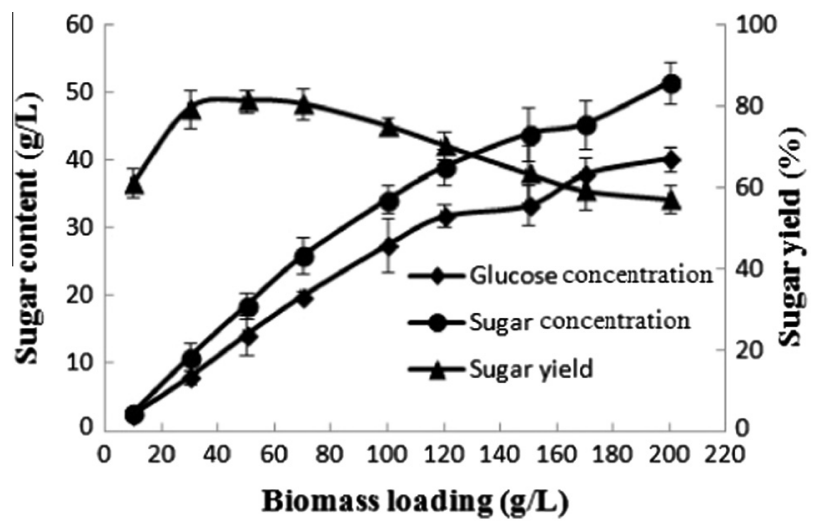

Fig. 2. Effect of biomass loading on sugar release during acid hydrolysis from microalgae biomass. Hydrolysis condition: $3 \%$ dilute sulfuric acid (v/v), temperature $121^{\circ} \mathrm{C}$, time $0.5 \mathrm{~h}$.

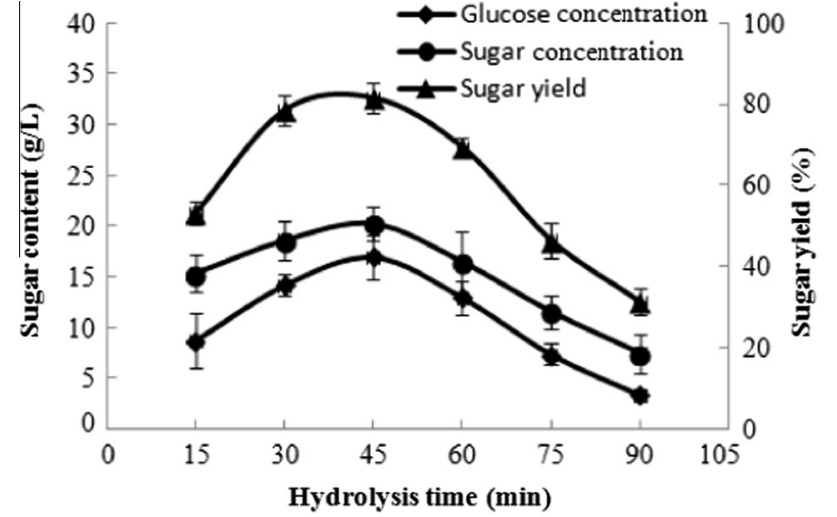

Fig. 3. Effect of hydrolysis time on sugar release from microalgae biomass. Hydrolysis conditions: $3 \%$ dilute sulfuric acid $(\mathrm{v} / \mathrm{v}), 7 \%(70 \mathrm{~g} / \mathrm{L})$ biomass loading $(\mathrm{w} / \mathrm{v})$, temperature $121^{\circ} \mathrm{C}$

Moreover, the hydrolysis time is also an important factor for the hydrolysis process determining. Referring to Fig. 3, there were big differences in the sugar contents and sugar yields as the prolongation of hydrolysis time. Total sugar and glucose concentrations linearly increased from $15.34 \mathrm{~g} / \mathrm{L}$ to $20.23 \mathrm{~g} / \mathrm{L}$ and $8.74 \mathrm{~g} / \mathrm{L}$ to $16.95 \mathrm{~g} /$ $\mathrm{L}$, respectively, with increasing hydrolysis time up to $45 \mathrm{~min}$ from $15 \mathrm{~min}$. And subsequently, total sugar and glucose concentrations dropped to $9.7 \mathrm{~g} / \mathrm{L}$ and $5.4 \mathrm{~g} / \mathrm{L}$, respectively, when hydrolysis time increase to $90 \mathrm{~min}$ at $121^{\circ} \mathrm{C}$.

\subsection{Lipid extraction after acid hydrolysis}

The total lipid of microalgae at the beginning was extracted by chloroform-methanol and the content was about 48.7\%. Although chloroform-methanol is effective in lipid extraction, large scale lipid extraction using chloroform is precluded by environmental and health risks. Hexane, despite being reported to be less efficient than chloroform, is less toxic and has minimal affinity toward nonlipid contaminant. Hence, hexane was adopted as the solvent to extract the lipid, and the lipid yield was calculated as the ratio between the lipid content determined by hexane to the lipid content determined by chloroform-methanol (Fig. 4). After $150 \mathrm{~min}$ reaction time, the lipid yield after hydrolysis reached $79.6 \%$ while that before hydrolysis was only $25.8 \%$, suggesting the acid hydrolysis increased the lipid release. The observation indicated that the microalgae cell wall structure became looser and the lipid could therefore be obtained more easily after dilute acid hydrolysis, and the similar results were also reported in other literatures (Harun and Danquah, 2011; Thu et al., 2009). In fact, enzymatic

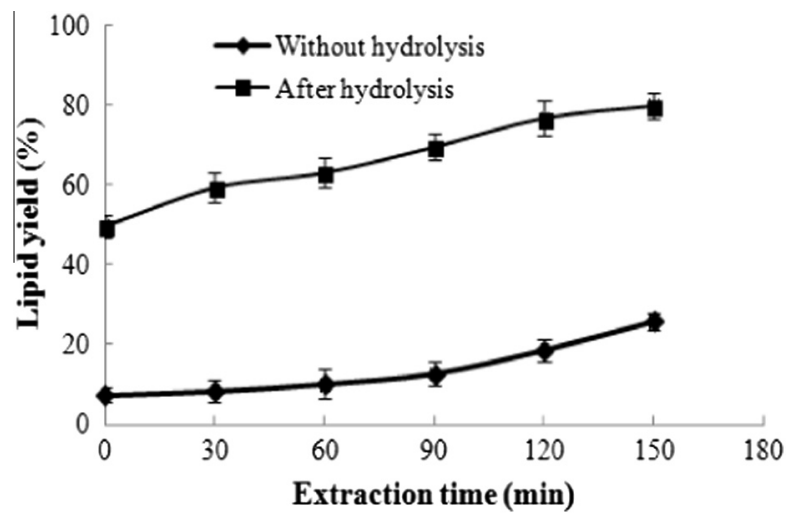

Fig. 4. Lipid recovery from Tribonema sp. with and without acid hydrolysis 
Table 1

Chemical composition of lipids and biodiesel from microalgae before and after hydrolysis.

\begin{tabular}{|c|c|c|c|c|}
\hline Chemical composition & Lipid (\%) (before hydrolysis) & Biodiesel (\%) (before hydrolysis) & Lipid (\%) (after hydrolysis) & Biodiesel (\%) (after hydrolysis) \\
\hline SE\&HC & $2.71 \pm 0.01$ & $2.53 \pm 0.01$ & $5.12 \pm 0.04$ & $4.85 \pm 0.01$ \\
\hline FAME & ND & $92.56 \pm 0.05$ & ND & $94.52 \pm 0.04$ \\
\hline FFA & ND & ND & $9.51 \pm 0.02$ & ND \\
\hline TAG & $68.14 \pm 0.01$ & $2.61 \pm 0.01$ & $67.76 \pm 0.04$ & $1.03 \pm 0.04$ \\
\hline DAG & $4.82 \pm 0.03$ & ND & $6.2 \pm 0.03$ & ND \\
\hline MAG\&PL & $24.44 \pm 0.07$ & $3.01 \pm 0.00$ & $9.04 \pm 0.01$ & $0.24 \pm 0.04$ \\
\hline
\end{tabular}

ND: not detected.

SE: sterol, HC: hydrocarbon, FAME: fatty acid methyl ester, FFA: free fatty acid, TAG: triacyglycerols, DAG: diacylglycerols, MAG: monoacylglycerols, PL: phospholipids.

hydrolysis was also adopted to loosen the microalgae cell wall to release the lipid (Fu et al., 2010).

\subsection{Biochemical compositions of lipid and biodiesel and fatty acid files of biodiesel}

The lipid of microalgae before acid hydrolysis was extracted by chloroform-methanol, while the lipid after hydrolysis was extracted by hexane-ethanol. As presented in Table 1, the difference between TAG contents in two kinds of lipid was not significant, however, the other compositions of the lipids, especially FFA and PL contents, changed. No FFA was detected in lipid before hydrolysis, while FFA content (\% of lipid) after hydrolysis increased to $9.51 \%$. Conversely, The PL content (\% of lipid) decreased significantly from $24.44 \%$ before hydrolysis to $9.04 \%$ after hydrolysis. The chemical compositions of biodiesel converted from two kinds of lipid were also listed in Table 1. TAG, DAG and MAG\&PL contents in lipid extracted with chloroform-methanol before acid hydrolysis decreased significantly from $68.14 \%, 4.82 \%$ and $24.44 \%$ to $2.61 \%, 0 \%$ and $3.01 \%$, respectively. In contrast, the content of FAME was $92.56 \%$ on the basis of biodiesel weight while no FAME was detected in lipid. For lipid extracted with hexane-methanol after acid hydrolysis, FFA (9.51\%) was totally transformed into FAME, and most of TAG, DAG and MAG\&PL were also converted into FAME. The conversion rate of triacylglycerols in lipid after hydrolysis reached $98.47 \%$, which is higher than that (96.17\% conversion rate of triacylglycerols) before hydrolysis.

Fatty acid profiles of lipid ultimately affects the quality of the biodiesel product (Knothe, 2005; Ramos et al., 2009), since the carbon chain length of saturated and unsaturated fatty acids affects biodiesel properties such as cetane number, oxidative stability and cold-flow properties (Smith et al., 2010). Fatty acid profiles of microalgae biodiesel from two kinds of lipid were determined by gas chromatography (Table 2). There was no significant difference between the carbon chain numbers and contents in different sources of biodiesel. FAME contains saturated and unsaturated carbon chain lengths from C14 to C20, and C16 was the dominant

Table 2

Fatty acid analysis of biodiesel converted from two kinds of lipids.

\begin{tabular}{lcc}
\hline $\begin{array}{l}\text { Fatty acid } \\
\text { composition }\end{array}$ & $\begin{array}{l}\text { Biodiesel (before } \\
\text { hydrolysis) }(\%)\end{array}$ & $\begin{array}{l}\text { Biodiesel (after } \\
\text { hydrolysis) }(\%)\end{array}$ \\
\hline C14:0 & $4.45 \pm 0.1$ & $4.46 \pm 0.3$ \\
C15:0 & $0.16 \pm 0.0$ & $0.15 \pm 0.1$ \\
C16:0 & $34.25 \pm 0.1$ & $33.86 \pm 0.0$ \\
C16:1 & $49.68 \pm 0.0$ & $49.59 \pm 0.0$ \\
C16:3 & $0.65 \pm 0.0$ & $0.74 \pm 0.1$ \\
C18:0 & $0.89 \pm 0.1$ & $1.03 \pm 0.0$ \\
C18:1 & $1.58 \pm 0.1$ & $1.59 \pm 0.0$ \\
C18:2 & $0.70 \pm 0.1$ & $0.73 \pm 0.1$ \\
C18:3 & $0.52 \pm 0.0$ & $0.56 \pm 0.0$ \\
C20:3 & $0.58 \pm 0.0$ & $0.61 \pm 0.0$ \\
C20:4 & $3.55 \pm 0.1$ & $3.58 \pm 0.2$ \\
C20:5 & $3.00 \pm 0.1$ & $3.10 \pm 0.0$ \\
\hline
\end{tabular}

carbon chain. The major components of biodiesel are saturated fatty acid (C16:0, 34.25\% and 33.86\%) and monounsaturated fatty acid (C16:1, 49.68\% and 49.59\%), which were considered to be better than polyunsaturated fatty acids for improving oxidative stability without any concomitant adverse effect on the cold properties of the diesel (Wang et al., 2013). Moreover, special attention should be taken to the polyunsaturated fatty acids with four or more double bonds (C20:4), which are susceptible to oxidation during storage and this reduces the acceptability as biodiesel (Angel et al., 2013). Therefore, two different sources of lipid were regarded as suitable materials for biodiesel production.

\subsection{Fermentative production of bioethanol}

After acid hydrolysis ( $3 \%$ sulfuric acid, $50 \mathrm{~g} / \mathrm{L}$ biomass-to-liquid, $121^{\circ} \mathrm{C}, 20 \mathrm{~min}$ ), the usability of microalgae hydrolysate as fermentation medium for bioethanol production using $S$. cerevisiae was investigated, and the initial glucose concentration after hydrolysis was $14.5 \mathrm{~g} / \mathrm{L}$. Fig. 5 showed the time course profile of residual sugar and ethanol concentrations during the bioethanol fermentation process. And a reference YPD medium with the same glucose concentration was regarded as control to compare the ethanol yield from microalgae biomass hydrolysate. Shortly after inoculation, the glucose concentration dropped rapidly, which were accompanied by a sharp increase in ethanol concentration in both control and hydrolysate. The glucose concentration in YPD medium decreased to ca.0.35 g/L from $14.5 \mathrm{~g} / \mathrm{L}$ while bioethanol concentration reached $7.83 \mathrm{~g} / \mathrm{L}$ after $16 \mathrm{~h}$ fermentation. For microalgae hydrolysate, higher glucose concentration $(4.94 \mathrm{~g} / \mathrm{L})$ than control remained in the hydrolysate in first $16 \mathrm{~h}$ and no obvious decrease in the glucose concentration was observed, which attributed to the lower ethanol concentration $(5.11 \mathrm{~g} / \mathrm{L})$ than control.

Although the maximum glucose utilization in YPD medium (97.6\%) was much higher than that (68.9\%) in microalgae

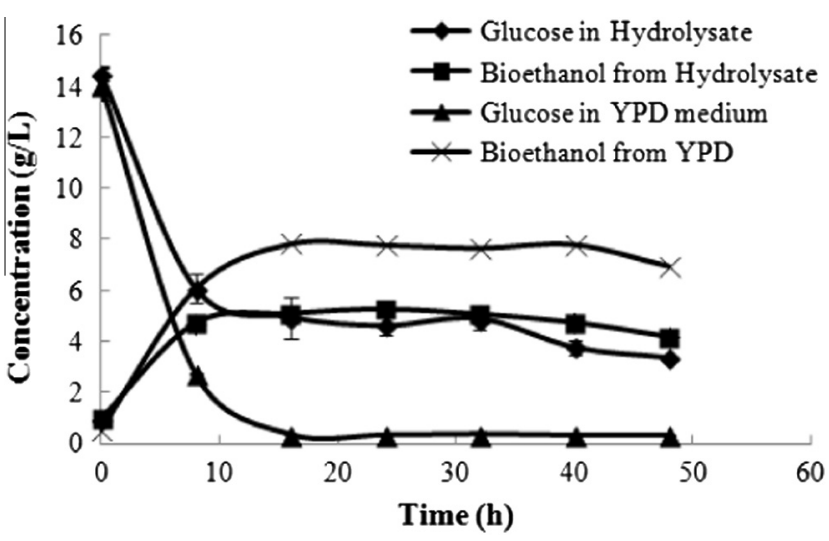

Fig. 5. Residual glucose and ethanol concentrations during the bioethanol fermentation process. 


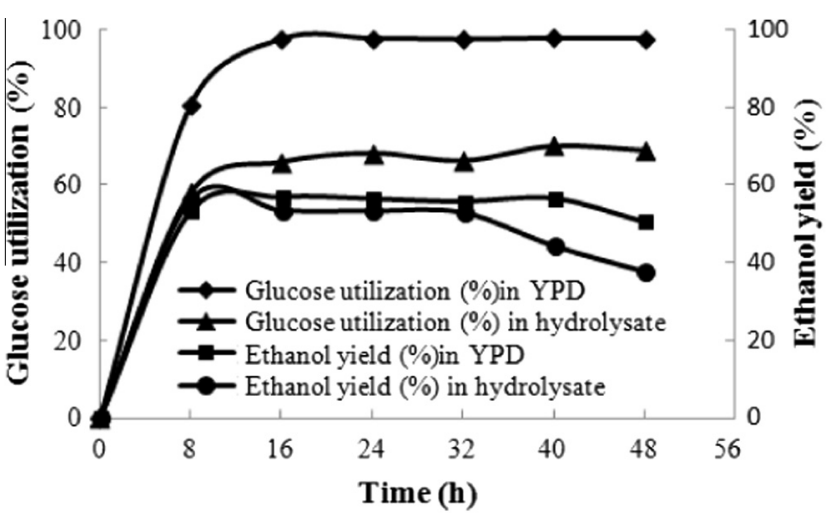

Fig. 6. Glucose utilization and ethanol yield during the bioethanol fermentation process.

hydrolysate, the ethanol yield of $37.6-56.1 \%$ (g ethanol/g glucose) in hydrolysate was slight lower than those of 50.5-56.9\% in control (Fig. 6). This is not surprising as the product (ethanol) and unwanted compounds (weak acids, furaldehydes and phenolic compounds) could negatively affect the growth of $S$. cerevisiae and the glucose utilization, which was significant hurdle for the ethanol fermentation from acid hydrolysate (Klinke et al., 2004). Therefore, the relevant countermeasures, such as deionization (Sun et al., 2011), dried and concentrated, and activated carbon absorption (Almeida et al., 2009) will be necessary to discussed in future to improve the glucose utilization an ethanol production in acid hydrolysate.

\section{Conclusions}

The feasibility of joint production of biodiesel and bioethanol from microalgae Tribonema sp. biomass enriched with lipid and carbohydrate content was confirmed. Dilute sulfuric acid was used to saccharify the cell wall to fermentable sugar and release lipid simultaneously. The maximum hydrolysis efficiency of $81.48 \%$ was approached at conditions of 3\% sulfuric acid (v/v), $50 \mathrm{~g} / \mathrm{L}$ biomass loading, $121^{\circ} \mathrm{C}$ for $45 \mathrm{~min}$. Subsequently, the intra-lipid was extracted successfully by hexane. With yeast $S$. cerevisiae, maximum ethanol yield of 56.1\% from $14.5 \mathrm{~g} / \mathrm{L}$ glucose in hydrolyses was reached.

\section{Acknowledgements}

The authors gratefully acknowledge financial support from Open project of State Key Laboratory of Motor Vehicle Biofuel Technology (Y3090416E).

\section{Reference}

Almeida, J.R.M., Bertilsson, M., Gorwa-Grauslund, M.F., Gorsich, S., Liden, G., 2009. Metabolic effects of furaldehydes and impacts on biotechnological processes. Appl. Microbiol. Biotechnol. 82, 625-638.

Angel, S., Rocio, M., Angeles, C., Alfonso, P., 2013. Culture aspects of Isochrysis galbana for biodiesel production. Appl. Energy 101, 192-197.
Chen, C.Y., Zhao, X.O., Yen, H.W., Ho, S.H., Cheng, C.L., Lee, D.J., Bai, F.W., Chang, J.S., 2013. Microalgae-based carbohydrates for biofuel production. Biochem. Eng. J. http://dx.doi.org/10.1016/j.bej.2013.03.006.

Chen, L., Liu, T.Z., Zhang, W., Chen, X.L., Wang, J.F., 2012. Biodiesel production from algae oil high in free fatty acids by two-step catalytic conversion. Bioresour. Technol. 111, 208-214.

Chisti, Y., 2007. Biodiesel from microalgae. Biotechnol. Adv. 25, 294-306.

Efremenko, E.N., Nikolskaya, A.B., Lyagin, I.V., Senko, O.V., Makhlis, T.A., Stepanov, N.A., Maslova, O.V., Mamedova, F., Varfolomeev, S.D., 2012. Production of biofuels from pretreated microalgae biomass by anaerobic fermentation with immobilized Clostridium acetobutylicum cells. Bioresour. Technol. 114, 342-348.

Fedosov, S.N., Brask, J., Xu, X., 2011. Analysis of biodiesel conversion using thin layer chromatography and nonlinear calibration curves. J. Chromatogr. A 1218, 2785 2792.

Fu, C.C., Huang, T.C., Chen, J.Y., Su, C.H., Wu, W.T., 2010. Hydrolysis of microalgae cell walls for production of reducing sugar and lipid extraction. Bioresour. Technol. 101, 8750-8754.

Guo, F.J., Wang, H., Wang, J.F., Zhou, W.J., Gao, L.L., Chen, L., Dong, Q.Z., Zhang, W., Liu, T.Z., 2014. Special biochemical responses to nitrogen deprivation of filamentous oleaginous microalgae Tribonema sp. Bioresour. Technol. 158, 1924.

Harun, R., Danquah, M.K., Forde, G.M., 2010. Microalgal biomass as a fermentation feedstock for bioethanol production. J. Chem. Technol. Biotechnol. 85, 199-203.

Harun, R., Danquah, M.K., 2011. Influence of acid pre-treatment on microalgal biomass for bioethanol production. Process Biochem. 46, 304-309.

Ho, S.H., Li, P.J., Liu, C.C., Chang, J.S., 2013. Bioprocess development on microalgaebased $\mathrm{CO}_{2}$ fixation and bioethanol production using Scenedesmus obliquus CNWN. Bioresour. Technol. 145, 142-149.

Huang, Y., Hong, A., Zhang, D., Li, L., 2014. Comparison of cell rupturing by ozonation and ultrasonication for algal lipid extraction from Chlorella vulgaris. Environ. Technol. 35, 931-937.

John, R.P., Anisha, G.S., Nampoothiri, K.M., Ashok, P., 2011. Micro and macroalgal biomass: a renewable source for bioethanol. Bioresour. Technol. 102, 186-193.

Klinke, H.B., Thomsen, A.B., Ahring, B.K., 2004. Inhibition of ethanol-producing yeast and bacteria by degradation products produced during pre-treatment of biomass. Appl. Microbiol. Biotechnol. 66, 10-26.

Knothe, G., 2005. Dependence of biodiesel fuel properties on the structure of fatty acid alkyl esters. Fuel Process. Technol. 86, 1059-1070.

Lee, S.J., Oh, Y.H., Kim, D.H., Kwon, D.Y., Lee, C.L., Lee, J.W., 2011. Converting carbohydrates extracted from marine algae into ethanol using various ethanolic Escherichia coli strains. Appl. Biochem. Biotechnol. 164, 878-888.

Logan, C., Ronald, S., 2011. Production and harvesting of microalgae for wastewater treatment, biofuels, and bioproducts. Biotechnol. Adv. 29, 686-702.

Lynd, L.R., Weimer, P.J., van Zyl, W.H., Pretorius, I.S., 2002. Microbial cellulose utilization: fundamentals and biotechnology. Microbiol. Mol. Biol. Rev. 66, 506577.

Mata, T.M., Martins, A.A., Caetano, N.S., 2010. Microalgae for biodiesel production and other applications: a review. Renew. Sustain. Energy Rev. 14, 217-232.

Ramos, M.J., Fernandez, C., Casas, A., Rodriguez, L., Perez, A., 2009. Influence of fatty acid composition of raw materials on biodiesel properties. Bioresour. Technol. 100, 261-268.

Razif, H., Michael, K.D., 2011. Influence of acid pre-treatment on microalgal biomass for bioethanol production. Process Biochem. 46, 304-309.

Silva, A.O.F.D., Costa, M.C., Lopes, A.C., Neto, E.F., Leitao, R.C., Mota, C.R., dos Santos, A.B., 2014. Comparison of pretreatment methods for total lipids extraction from mixed microalgae. Renew. Energy 63, 762-766.

Smith, P.C., Ngothai, Y., Nguyen, Q.D., O'Neil, B.K., 2010. Improving the lowtemperature properties of biodiesel: methods and consequences. Renew. Energy 35, 1145-1151.

Sun, H.Q., Lu, X.M., Gao, P.J., 2011. The exploration of the antibacterial mechanism of $\mathrm{Fe}^{3+}$ against bacteria. Braz. J. Microbiol. 42, 410-414.

Szczodrak, J., 1988. The enzymatic-hydrolysis and fermentation of pretreated wheat straw to ethanol. Biotechnol. Bioeng. 32, 771-776.

Talukder, Md.M.R., Das, P., Wu, J.C., 2012. Microalgae (Nannochloropsis salina) biomass to lactic acid and lipid. Biochem. Eng. J. 68, 109-113.

Thu, N.M., Choui, S.P., Lee, J.H., Sim, S.J., 2009. Hydrothermal acid pretreatment of Chlamydomonas reinhardtii biomass for ethanol production. J. Microbiol. Biotechnol. 19, 161-166.

Wang, H., Gao, L.L., Chen, L., Guo, F.J., Liu, T.Z., 2013. Integration process of biodiesel production from filamentous oleaginous microalgae Tribonema minus. Bioresour. Technol. 142, 39-44. 